\title{
LAICISMO: TRAMPA DE IDOLATRÍA 0 NIHILISMO CONSTITUCIONAL
}

\section{LAICISM: IDOLATRY TRAP OR CONSTITUTIONAL NIHILISM}

\author{
Samer Alnasir \\ Universidad Nacional de Educación a Distancia, Madrid, España \\ samer@alnasir.org \\ https://orcid.org/0000-0002-9232-9035
}

Recibido: julio de 2021

Aceptado: septiembre de 2021

\begin{abstract}
Palabras clave: Laicismo, religión y Estado bajo el Antiguo Régimen, religión y la Revolución francesa, idolatría constitucional, nihilismo constitucional.

Keywords: Laicisim, religion and the State under old regime, Religion and French Revolution, constitutional idolatry, constitutional nihilism.
\end{abstract}

Resumen': Soberanía y laicismo son dos conceptos que están adquiriendo protagonismo en los debates públicos de su país nativo, Francia. Este artículo propone abordar ambos desde dos perspectivas. La primera, etimológica, intenta indagar el origen del concepto de «laicismo» desde el siglo xv y construir una definición conforme a su uso dado durante el Antiguo Régimen y durante el primer siglo de la revolución hasta la ley de neutralización-emancipación de 1905. La segunda, poner de relieve el antagonismo que suponía la convivencia de ese término con la soberanía propugnada por la revolución y los postulados centristas de los imperios que alimentaron la ideología de la ley de separación de 1905. La conclusión que se pretende alcanzar, y enlazar para sucesivos trabajos, es que el resurgimiento del concepto y su asalto a la Constitución de 1958 consiste en un antagonismo, tanto con su etimología como con la propia constitución, causando, más que idolatría, un entramado de nihilismo constitucional, o incluso una especie de blasfemia normativa a favor del populismo político.

Abstract: The concept of sovereignty and laicism still being instrumented into different projection to that's which have been conceived and used for through the french revolution and the old regime. This article is not to discuss that, but to delight how another concept deduced from it becomes antagonistic with it in the French context. Laicity referred to the French $\mathrm{V}$ constitution, or the act of 1905, it's not what it appear, and mostly known in the french literature, this article is to reject all that, and go toward an etymological construction of the concept into the french politics since XV century. Then to examination who

1. El presente artículo, que forma parte de un proyecto de investigación sobre la emergencia del laicismo como lema populista, ha sido presentado en la edición 2021 de la Escuela de Humanidades y CC. Sociales, RECAST de la COST Action CA 16211. Agradezco los contribuyentes comentarios hechos entonces, además de los del profesor Francisco Colom González al primer borrador del trabajo.

Revista Internacional de Pensamiento Político - I Época - Vol. 16 - 2021 - [333-355] - ISSN 1885-589X 
and how the old regime, and the XIX century have been involved with the religious beliefs then to answer the questions: does the revolution have been laic or atheist? The answer is useful to go forward the examination of the french act of the separation of the State from the churches of 1905 , and to determine if that act has been laic or atheist. The questions of how the idea of laicism has been reversed into the interwar period thus to the 1958 constitution to be developed in a further work, but the conclusion proposed here is the evidence of constitutional inter-contradiction and reversed usage of the concept which is being instrumented today further then a constitutional idolatry, but a constitutional nihilism.

\section{Preliminares}

El dogma de la soberanía del pueblo se convertirá en un instrumento de la tiranía y, durante algún tiempo, el pueblo permitirá ser oprimido en nombre de su soberanía. Constant, 1872: LIV2

El laicismo o la laicidad están ocupando, desde los últimos años, el centro de los debates públicos en su país natal, Francia, pero también, y por extensión, en muchos otros contextos socioculturales distintos, incluso lejanos al entorno europeo, o con neologismos ambiguos, como lo es el caso en castellano. Más recientemente, se ha convertido en el lema central del

2. La traducción es nuestra, tanto de este fragmento como del resto de los textos en francés, en los que se adaptó la puntuación -a veces ausente o discutible- para una mejor comprensión en castellano. debate público francés. Un neoviralismo mediático, así como populista, que se ha vuelto en el reclamo más rentable tanto para derechas como para izquierdas, para liberales como para conservadores, lo mismo para estadistas que para anárquicos. Todo el mundo reclama, postula y defiende el laicismo.

El presente artículo no se centra en abordar este fenómeno populista ni mediático, ni el modo de su instrumentalización política, sino que pretende llenar un vacío de un análisis empírico y holístico para abordar el laicismo y afinar su sentido jurídico en su lugar de origen, Francia, y desde dos perspectivas. La primera, indagar en la etimología del concepto desde la modernidad, pasando por su conjugación revolucionaria hasta llegar a la llamada «ley del laicismo» de 1905, a la que de aquí en adelante nos referiremos como ley de la separación o de la emancipación -ya que el principal cometido de este artículo es negar la consideración del laicismo a esa ley-. La segunda perspectiva, que supone el punto de partida, es contrastar el protagonismo del término «laicismo» frente al paradigma de la soberanía que promovió la revolución. Es decir, abordar el problema desde un esquema antagónico entre laicismo y soberanía como dos preceptos contradictorios, la cual sería la hipótesis que se persigue demostrar. Por tanto, el presente estudio delimitará el marco temporal hasta la promulgación de la ley de separación de 1905, desde el primer concordato de la modernidad, de 1516, hasta la promulgación de la ley de separación de 1905 -aunque se aludirá también en las conclusiones al uso del término en la Constitución de la Quinta República de 1958-. Es decir, dado el margen de extensión, el presente artículo dejará pendiente de ulteriores estudios la evolución durante 
periodo subsiguiente, periodo de tergiversación, desde la promulgación de la ley de separación hasta la resurrección perversa del concepto de laicismo y su constitucionalización en 1958, allanando así el camino desde las conclusiones del presente, que abordarán el problema desde la idolatría hasta el nihilismo constitucional.

\section{La soberanía, ficción revolucionaria y Estado}

El paradigma de la soberanía ha sido el foco liberador del Estado de otros poderes supra o infraestatales. Bodino lo define como seña del bien común de la nación, un poder absoluto y perpetuo (Juri, 2020; Pendás, 2020), vínculo y pilar cardinal de la esencia del Estado (Conde, 1935). Una idea de exclusividad excluyente de todo dios $\mathrm{u}$ otro poder que entorpeciera la voluntad del pueblo, la soberanía se postulaba lugartenencia de Dios como un dios de voluntad general. La suma de todos sustituye la interferencia de un influyente de incógnito por un influyente fehaciente, manifiesto, material y positivo, a la vista de todos: el poder popular, independiente y libre. Se impone como la negación de la negación, la negación de cualquier otro poder que se enfrenta a su negación, impidiendo así todo reto a su principio genealógico de independencia, que alteraría el orden de su jerarquía. La soberanía se podría interpretar como una interpretación exponencial del ateísmo, al restringirse al poder material de los sujetos, el pueblo y sus representantes. Es un principio de totalidad presupuestada para fundar y fundamentar unitariamente por los hombres un totalitarismo necesario como exigencia para neutralizarse y superar la crispación alimentada por misterios teleológicos, heterogéneos y de improvisación, imponiendo así una constelación de consecuencialismo y pertenencia. Para consolidar su trinchera, la soberanía impone por sí misma hacer sitio a su propia exigencia, como discriminante, forjándose así como un paradigma de principios excluyentes y sin retorno.

La ruina de los bellos principios de la idea de soberanía emergió desde su propio entramado por una sublevación maliciosa de la voluntad salvaje de los hombres -uno o varios-, que emprendieron rápidamente el camino hacia la cima para instrumentalizar su neutralidad y manipular así el conjunto del esquema para su propio interés. En una carta de Robespierre a La Fayette sobre los poderes de la Asamblea Nacional y el rey, aquel le advirtió de que «el patriotismo ambicioso que pretende postularse el legislador será más fatal a la libertad que el incivismo mismo de todos los enemigos, dará la señal de anarquía de la guerra civil y de la disolución del Estado» (Robespierre, 1840a: 446). Esa es la primera advertencia a la que podemos aludir hoy, lo que Müller pasó a llamar o a entender como «postulados de militancia» o de democracia militante (Müller, 2012). Aunque, en este caso, el propio Müller la dote de sentido positivo, entendiéndola como protectora y consolidadora de regímenes constitucionales (Müller, 2016).

Fue la malicia de unos hombres que se empeñaron en parasitar su exclusividad para prescindir de sus oponentes. Otros hombres identificados con distintos rasgos teóricos, ideológicos, raciales, conductuales, o simplemente buscando en cualquier otro argumento de polarización para agitar su postulado de otredad (othering). Es

3. Se propone españolizar el concepto othering, como se ha hecho en francés con autrance, en lugar de seguir manejando un extranjerismo, ya 
decir, el paradigma de positividad de los hombres se volvió más humano que los humanos, puesto que todos los supuestos de otredad agitados por los sublevados no revestían otros postulados que los propiamente humanos: sexo, raza, conducta, ontología y hasta variante de habla 4 .

Por otro lado, para consolidar su positividad y su negativa a toda improvisación, la soberanía imponía un entramado sistemático, funcionalmente interdependiente, llamado sistema jurídico, para negar con ello la improvisación teleológica del Antiguo Régimen, estructurado como un ordenamiento jurídico. Es decir, un esquema normativo estético interoperante frente a un entramado de tópicos acumulados por bulas, jurisprudencia y multitud de providencias revestidas bajo distintas rúbricas: decretos, órdenes, sentencias, directrices y hasta instrumentos estratégicos $^{5}$. Si el derecho no es otra cosa que

que el precepto se refiere a esa misma connotación de exclusión, expulsión, que lo podemos acuñar en castellano como otredad, salvo que se opongan las autoridades filológicas.

4. Las variantes de habla constituyen un factor tanto de exclusión como de populismo. En varios contextos sociales, son referidos con denotación negativa de exclusión y/o de clase social, pero en muchos otros son aprovechados como instrumentos populistas y de identidad. Alnasir abordó el dilema desde el paradigma de la identidad antropológica, cuando las variantes de habla son tomadas como esquema de identidad, incluso definidas como relevo intercultural causado por un golpe social, como se definió en el caso de Iraq desde su invasión en 2003, que presenta una sublevación lingüística en su lenguaje político, jurídico y hasta jurisdiccional. Véase Alnasir (2019), citado en Alnasir (2021a: 485-519), también Alnasir (2021b).

5. Los clásicos asentaron la teoría del Estado desde varias perspectivas, bien como un producto de la voluntad general (Hobbes, 1999: 50), bien como producto del monopolio de la coacción colectiva, Monopol legitimen physischen Zwan- la organización misma de la vida social, como decía Durkheim (en Commaille, 1991: 13), el del Antiguo Régimen -tanto derecho como sociedad- se regulaba desde fuera de la sociedad, mediante un poder vicario, invisible y ajeno al tejido social, llamado espíritu divino, que violaba la soberanía del poder social, contaminando sus perspectivas de decisión.

Antes del desastre de la Segunda Guerra Mundial y del armazón schmittiano, la escuela publicista francesa ya tenía sus rifi-

ges (Weber, 2014). También, como un sistema jurídico en sí mismo (Kelsen, 2000: 155). Para el publicismo, tanto el Estado como la soberanía y los derechos subjetivos no son realidades, sino principios auxiliares para la definición del Estado, no debiendo confundirse el Estado con un ordenamiento jurídico concreto, como señala Troper (2001: 150). Un Estado soberano, en conclusión, es un ente unitario, sea que uno se refiera con esto a una unidad lógica o teológica (Engisch, 1960: 42). Es el resultado de la conquista de un grupo humano aglutinado por el contrato como reflejo de la lucha de clases para asegurar el interés general (Troper, 1994: 244). O bien, stricto sensu, el Estado se habría formado como una comunidad de hombres asentados sobre un territorio determinado, que impusieron la suma de la sus voluntades para la dirección y la coerción conjunta, como señala Malberg (1962: 7). De hecho, Duguit (1918: 30) rechaza la dimensión territorial del Estado como elemento constitutivo indispensable a favor de un elemento subjetivo de la personalidad del Estado, con la soberanía como elemento indispensable para la formación de este. Ostentar el dominio sobre el territorio o la agrupación humana no suponen por sí el esquema del Estado sin una soberanía tanto objetiva, sobre el territorio, como subjetiva, sobre los individuos; precisamente esa sería la diferencia entre un Estado y una organización mafiosa o terrorista que ocupe un territorio ajeno o, como ponía de ejemplo Duguit, los Estados bajo protectorado o federados (Duguit, 1928: 129-30). El citado autor consideró que el territorio es el elemento subjetivo del Estado, apenas constitutivo de su personalidad jurídica, pero no de su identidad normativa Duguit (1928: 51-53). 
rrafes sobre la paradoja del Estado y la soberanía, en cuanto a un poder absoluto y sin límites sobre el que descansa el mismo poder de la ley, Herrschaft. El decano Duguit, contestando a Malberg, delimitaba la maniobrabilidad del Estado por los principios del derecho y de la moral, suscribiendo así los valores metajurídicos propuestos por Jellinek (Duguit, 1928: 130). Más bien se abogaba por la soberanía en el sentido estricto de poder creador del derecho, un poder espontáneo de la muchedumbre (Duguit, 1928: 94), y no un absoluto del Estado. En palabras de Duguit:

En tanto que voy teniendo más edad, sigo afirmando enérgicamente que el derecho existe como una regla imperativa, encima e independientemente del Estado, que es una creación espontánea de la muchedumbre social, de la conciencia social o, si lo preferimos llamar así, de la suma de conciencias individuales, que se aplica tal cual a todos los individuos, tanto a los gobernantes como a los gobernados. Es una creación arbitraria del Estado cuyo estudio no requiere ni un minuto de esfuerzo, si oponemos la moral social al derecho, crearemos una regla moral sin fuerza y un derecho sin valor moral. Por tanto, la idea inspirada por Carré de Malberg conducirá fatalmente, salvo que él se retracte, a otorgar una potencia sin límites al Estado y un bagaje jurídico a la política del absolutismo ... (Duguit, 1928: 103-4).

La soberanía, según Duguit, descansa sobre cuatro pilares: (1) monopolio de unicidad sobre el territorio; (2) indivisibilidad, indiseccionabilidad y circunscripción única; (3) imparcialidad, ya que supone la capitalización del conjunto que no permite su ruptura ni su alineación diseccional; (4) perpetuidad, por la misma razón de su imparcialidad, es un ser continuo del conjunto ontológico que la compone (Duguit, 1928: 118). Aun con ello, un año antes Duguit ya venía asentando que:
En tanto que voy teniendo más años ${ }^{6}$, cuanto más estudio y profundizo en el problema del derecho, más me convenzo de que el derecho no es una creación del Estado, sino que existe fuera de él y de que la noción del derecho es perfectamente independiente de la noción del Estado y de que se impone al Estado al igual que lo hace a los individuos (Duguit, 1927: 104).

Las advertencias y la posición de Duguit no tuvieron ni eco ni éxito entre sus coetáneos. Tanto De Malberg como Hauriou siguieron entregados al absolutismo de la soberanía después de su muerte, en 1928, y en línea con la idea de la soberanía parlamentaria anglosajona, según la cual el Parlamento, en el ejercicio de esta, puede hacer cualquier cosa menos convertir un hombre en una mujer. Abonaron así el terreno para el desastre, plenamente legal y normativo, de la soberanía absoluta del Tercer Reich, guiado por Karl Schmitt. La soberanía absoluta acabó siendo instrumento de un derecho punzante, más soberano que humano. Una soberanía más arbitraria que la teocracia, a pesar de depender del pueblo, agitada por un individuo mediante minuciosas técnicas de agitación populista. Es decir, una soberanía estrictamente humana, pero aberrantemente ajena a la humanidad.

En lo sucesivo, se indagará en el principal elemento contaminador de la soberanía, la religión, como un poder teocrático -también como esquema moral- que se antepone a esta y condiciona su maniobrabilidad. Hablamos de la religión como clero oligárquico o de la religión como

6. La expresión del decano Duguit, «plus... tant que j'avance en âge...», con algunas variantes, aparece de forma reiterada en sus últimos escritos, sobre todo en la última década de su vida, por lo que la traducción intenta conservarla en la medida de lo posible, aun forzando ligeramente la sintaxis. 
moral pública entendida como laicismo, pero limitando el discurso a la búsqueda etimológica de los términos, laicismo y religión, y su envoltura-interés con el Estado y el derecho, dado que, como decía Ihering, «un derecho positivo no puede considerarse sin la categoría del interés» (Viehweg, 1964: 127).

\section{Soberanía y religión: el entramado histórico}

Para poder entender empírica y holísticamente el entramado de la hoy llamada laicidad-religión, o religión laica, es preciso adentrarse en sus raíces y hacerlo en dos aspectos. El primero consiste en buscar el origen etimológico del término «laicismo» y qué uso histórico se le daba, con qué efectos y connotaciones. El segundo, en explorar el desarrollo histórico de las relaciones eclesiásticas con el Estado, tanto bajo el Antiguo Régimen como con la incipiente revolución, hasta llegar a la llamada «ruptura de 1905».

Sin adentrarnos en la antigüedad, el primer concordato moderno entre la Iglesia y el Antiguo Régimen sería el del año 1516. Consiste en tres principales ejes: (1) el catolicismo es la religión única del Estado, que ya venía encabezada por el jefe del Estado rubricado como príncipe laico de la Iglesia, según definición dada en la Pragmática de Bourges del año 1438; (2) la interdependencia internacional de la Iglesia, a pesar de estar encabezada por el jefe del Estado, mantenía una unión ecuménica con la Santa Sede, representada como una interdependencia orgánica nacional y doctrinal internacional; (3) el culto católico consiste en servicio público del Estado administrado por la rama eclesiástica como uno de los ejes de la función pública, equi- parado a las demás ramas del servicio público estatal (Duguit, 1907: 3 y 13).

De hecho, la pragmática de Carlos VII, de 12 de julio de 1790, establecía el mismo mecanismo de elección y nombramiento de los obispos departamentales que el que se llevaba a cabo para seleccionar y nombrar las cabezas de la Administración, los prefectos, salvo el protocolario trámite de comunicárselo al papa, en su condición de máximo representante de la Iglesia universal, interesando la unión de la fe (Duguit, 1907: 11). La adopción de esta pragmática entonces y el mecanismo que impone causó la reacción en la Santa Sede, llevando al papa Pío VII a aprobar la ley de 13 de abril de 1791 sobre el estado civil del clero francés, dejando nulos todos los nombramientos y juramentos hechos en virtud de la pragmática de Carlos VII y dando un plazo de cuarenta días a todo aquel que tomó posesión para retractarse. Es decir, fue un tiempo de turbulencias y dinámicas corrosivas entre la Santa Sede y el nuevo Estado de la revolución en forma de luchas por la hegemonía, la independencia y el establecimiento de la soberanía, que fue el principal valor de la revolución.

Amanecida la revolución, en el año 1792 se presentó una iniciativa por parte de la comisión de finanzas, dirigida a la Convención Nacional, con dos propuestas antagónicas: la primera, para suprimir los impuestos inmobiliarios y los de las patentes industriales, y la segunda para suprimir el sostenimiento público de salarios de los ministros de culto de cada confesión (Buchez, 1835: 448-49). La propuesta recibió duras críticas, primero por Bazire, quien se postuló para abatirla en sus dos sentidos (Buchez, 1835: 449), y luego por Robespierre, el sublime ideólogo de la revolución, que pasa a liderar la 
posición contraria a dicha iniciativa, que, efectivamente, no salió adelante.

Robespierre se oponía no por espíritu proteccionista de la bicefalia del Estado y el sostenimiento de la religión como tal, sino por una razón estratégica, de técnica legislativa y carácter formalista, considerándola, ante todo, inoportuna para la revolución, peligrosa para la política y mala para las finanzas (Robespierre, 1840a: 325). Se dirigió ardorosamente a la Convención para señalar que los legisladores pueden apoyar a la razón, pero no suplirla, y lo hizo en los siguientes términos:

Legisladores, podéis abundar esta época por leyes generales, por una constitución libre que aclare los espíritus, regenere las mentes y eleve las almas a la simplicidad natural, pero no por un decreto circunstancialista ni por especulación financiera. Si el pueblo se desembarazase de la mayor parte de los prejuicios supersticiosos, nada le interesaría más que considerar la religión como institución sometida a las provisiones políticas. El dogma de la divinidad impregna los espíritus, y ese dogma está vinculado al culto del pueblo, que lo lleva profesando hasta ahora y que forma parte de sus ideas morales. Atacar este culto es atentar directamente contra la moralidad del pueblo. Si una sociedad de filósofos se fundara sobre la base de otra, la consentimos, pero los hombres ajenos a su meditación profunda confundirán los motivos de la virtud con los principios de la religión, no podrán percibir el sacrificio del culto acometido por el Gobierno por los intereses de otra naturaleza (Robespierre, 1840a: 326-27)7.

7. El texto original reza literalmente lo siguiente:

Législateurs, vous pouvez hâter cette époque par des lois générales, par une constitution libre qui éclaire les esprits, régénère les mœurs et élève toutes les âmes à la simplicité de la nature; mais non par un décret de circonstances et par
Eso pone en evidencia que la revolución sí podría haber albergado perspectivas neutralizadoras del Estado de la religión, pero parecen ser más humanistas. Se presumía el interés del pueblo en sus valores superiores, en su moral, o en lo que considera como tal, por lo que respecta a esta consideración como una delimitación de intervención mínima.

No prospera, por tanto, la propuesta del decreto, que en el fondo tampoco suponía un divorcio total, sino una desaceleración del sostén financiero, ya que apenas se refería a los salarios de los ministros de culto, y no del conjunto institucional de la Iglesia, que seguía siendo encabezada por el nuevo jefe del Estado posrevolucionario. Este cargo en la nueva era pasa a ser ocupado por el primer cónsul, Napoleón Bonaparte, en 1802, como veremos enseguida.

\section{Napoleón Bonaparte y la religiosidad}

Los cambios regulativos los podemos remontar más bien a Napoleón, y no tanto a la propia revolución, aunque también

une spéculation financière. Si le peuple est est dégagé de la plupart des préjugés superstitieux, il n'est point dispose à regarder la religion ellemême comme une institution indifférente ou soumise aux calculs de la politique. Le dogme de la divinité est gravé dans les esprits, et ce dogme, le peuple le lie au culte qu'il a professé jusques ici; et à ce culte, il lie au moins en partie le système de ses idées morales. Attaquer directement ce culte, c'est attenter à la moralité du peuple. Qu'une société de philosophes fonde la sienne sur d'autres bases, on le conçoit, mais les hommes qui, étrangers à leurs méditations profondes, ont appris à confondre les motifs de la vertu avec les principes de la religion, ne peuvent voir sans effroi le culte sacrifié par le gouvernement à des intérêts d'une autre nature. (Robespierre, 1840a: 326-27) 
durante ese tiempo, desde la emergencia de la revolución al ascenso de Napoleón al poder, se hayan producido intensos debates, como el ya visto del proyecto de 1792. Con posterioridad a este, se firmó un efímero concordato, en 1801, que apenas un año más tarde, en 1802, fue enmendado unilateralmente por Napoleón mediante una ley.

En lo que se refiere a Napoleón, tanto en política como en táctica de gobernanza, Sevestre (1905: 4) resume su definición de este gobernante en que fue un buscador de pacificación religiosa, pero, eso sí, pacificación en términos de maliabilidadflexibilidad para la gobernanza, es decir, instrumentalización populista ${ }^{8}$.

Desde Roma, el 7 de junio de 1797, Napoleón escribe al director ejecutivo de la República rindiendo cuentas de sus avances militares y le informa de que «actualmente la curia romana se encuentra reunida para decretar una bula que prohíba a todo aquel que pretenda postular la guerra civil de resistencia bajo pretextos religiosos» (Bonaparte, 1858: 374). El 13 de septiembre del mismo año, en otra misiva a Talleyrand, el entonces ministro de Asuntos Exteriores, le dice que «con ejércitos como los nuestros, para quienes todas las religiones son iguales, mahometanos, coptos, árabes, idólatras, etc., nos es indiferente mientras nos respeten, tanto los unos como los otros» (Bonaparte, 1859: 294).

La instrumentalización religiosa ya venía impregnada en sus anteriores discursos

8. En otro trabajo del autor de este artículo, en proceso de publicación, se intentó examinar el populismo colonial de Napoleón y su instrumentalización religiosa en sus guerras de invasión a Italia, Egipto, y su posterior modo de obrar en el consulado. y declaraciones. En su arenga ante el pueblo de Lombardía del 19 de mayo de 1796, Napoleón afirma que el «respeto a las propiedades, las personas y el respeto a la religión de los pueblos y sus sentimientos son los principios de la República Francesa y de la armada victoriosa en Italia» (Bonaparte, 1858: 297). La misma fórmula la podemos encontrar poco después en sus proclamas de la República de Venecia, de 29 de mayo de 1796 (Bonaparte, 1858: 332) y del Tirol, el 30 de agosto de 1796 (Bonaparte, 1858: 573). Incluso en el artículo cuarto del convenio secreto suscrito entre Napoleón y Faipoult, en nombre de la República Francesa y la República de Gênes, del 5-6 de junio de 1797, establecía que la comisión encargada de redactar la constitución y todas las leyes observará no hacer nada en contra de la religión católica (Bonaparte, 1859: 94-95).

La afinidad religiosa de Napoleón es muy ajena al catolicismo como ideología, y más bien se plasma dentro de una táctica de pacificación religiosa dirigida al asentamiento de una nueva religión fundada en línea con los valores del monopolio revolucionario y napoleónico ${ }^{9}$. Napoleón entiende el catolicismo como esa «organización que ha reclutado bajo su imperio a los pueblos civilizados, formando sus almas, inspirando sus cánticos, poesías, artes, trazando sus memorias nacionales, apropiándose, incluso, de sus símbolos nacionales, tanto vencidos como vencedores» (Sevestre, 1905: 5). Por ello, tras la llegada del feroz Napoleón Bonaparte al consulado, delega en su hermano, José

9. Más adelante se hará referencia a varios textos tanto de la época napoleónica, como de su legado posterior, que se refieren al servicio de culto como instrumento de tranquilidad social o tranquilidad pública. 
Bonaparte, para que el 15 de julio cierre la negociación del nuevo concordato. El 7 de septiembre 1801 lo aprueba prometiendo su aceptación para que así se produzca el consiguiente intercambio de firmas entre los plenipotenciarios el 10 de septiembre en París (Sevestre, 1905: 39 y 218).

El nuevo concordato se refiere principalmente a la concentración de todo el poder en manos del primer cónsul, quien por primera vez pasará a nombrar los obispos (art. 4), establece un nuevo concierto de organización territorial (art. 2), además de que el artículo 6, somete, mediante juramento, a los nuevos obispos, única y exclusivamente a la fidelidad a Dios, los Evangelios y la República, sus leyes y su Gobierno, sin ninguna alusión a la jerarquía romana. El nuevo concordato recobra la soberanía del Estado usurpada por la imbricación con la curia romana. Recupera, sobre todo, la soberanía unilateral para regularizar una institución que depende plenamente del Estado, imponiéndola, además, el imperio de la ley, mediante juramento, al prohibirle afiliación alguna o simpatía hacia ninguna otra autoridad extranjera: solo Dios, los Evangelios, la República y sus leyes.

Sin embargo, el año siguiente, el 8 de abril de 1802, Napoleón promulga una ley, Ilamada del 18 Germinal, por cuyo preámbulo ratifica el concordato del año anterior, aunque altera sustancial y unilateralmente sus matices y, además, ratifica las anteriores leyes reguladoras del culto católico y protestante del 15 de julio de 1801, anteriores a la firma del concordato. Además, en el caso del culto católico, concentra la autoridad dogmática en manos del Estado, pues el artículo primero prohíbe la recepción, publicación, impresión, así como poner en ejecución ninguna bula, orden, abreviatura, decreto ni mandato emitido por Roma sin la previa autorización del Gobierno de la Repúbli$\mathrm{ca}^{10}$. Es decir, la prohibición no consiste en una validez ipso facto de las disposiciones de la curia romana, sino que se extiende más allá, al prohibir hasta su impresión, difusión o puesta en debate, tanto pública como académica. Una similar disposición, en el reglamento paralelo referente al culto protestante, impone la tutela del Estado sobre todos sus ejercicios doctrinales y dogmáticos, estableciendo que no se podrá promulgar ni difundir ninguna información ni material de doctrinal sin la previa autorización del Estado ${ }^{11}$. Igualmente, en lo que se refiere a la Iglesia protestante, prohíbe toda forma de relación con cualquier autoridad o potencia extranjera, además de concentrar sus seminarios en la figura del primer cónsul, quien nombrará directamente sus profesores. Es decir, el Estado liberaliza el ejercicio de ambos credos, sí, pero con férreas medidas nacionalizadas y centralizadas por el Estado, que se postula como único titular de la soberanía.

Napoleón liberaliza el culto protestante, dado que el concordato de 1516 y las sucesivas declaraciones del credo, de 1682, y de la tolerancia, de 1787, establecían que el Estado defendía el credo católico como único en el territorio francés. De ahí que en la ley del 1802 se autorice el ejercicio del credo protestante, pero con importantes restricciones y/o discriminaciones en comparación con el caso católico. Eso sí, sin ninguna alusión a las demás con-

10. Similar al regium exequatur o pase regio en España.

11. Tales imposiciones manifiestan la recuperación de la soberanía, entendida como titular de la última palabra, pues de poco valdría la palabra de ningún poder sin que el soberano último, el Estado, la refrendase como válida. 
fesiones, ni a la reformista luterana ni a la israelita, ni mucho menos la islámica, a pesar de que Napoleón recién regresaba de Egipto, donde, supuestamente, había declarado que profesaba el islam y manifestado su simpatía hacia esa religión. No obstante, cabe destacar que uno de los principios del contraproyecto propuesto por la curia romana durante las negociaciones del concordato el 15 de mayo 1801 establecía que «el primer cónsul profesará la religión católica...» (Sevestre, 1905: 485), algo que, al parecer, desaparece totalmente del artículo cuarto del texto firmado en septiembre (Sevestre, 1905: 218).

El envolvimiento con la República se extiende, además, al ejercicio del culto mismo. El artículo primero de la ley referida a la Iglesia católica define la envoltura del Estado con la religión católica, pero con carácter nacional, y dice que «la religión católica, apostólica y romana será libremente ejercida en Francia. Su culto será público, y conforme a las normas de policía que el Gobierno juzga necesarias para la tranquilidad pública». El artículo 51 impone la obligación de incluir en la celebración de la misa una plegaria por el buen hacer de los cónsules y por la prosperidad de la revolución, que igualmente se impone al culto protestante mediante el artículo tercero de su reglamento. La misma obligación se introduce en el inciso final del artículo primero de la ley constitucional de 1875, denominada Constitución de la Tercera República, a la que volveremos más adelante en el análisis de la ley de 1905.

Por su parte, el Consejo del Estado, sobre el proyecto de la ley de 1802, dictaminó que:

Todo Gobierno ejerce dos marcos de poder en materia religiosa: el que se refiere esencialmente al magisterio político en todo lo que interesa a la sociedad, y aquel protector de la religión misma. Por el primero, los poderes públicos y el Gobierno tienen el derecho de reprimir eventualmente ${ }^{12}$ toda empresa que pretenda entorpecer al poder público y la tranquilidad del Estado. Por el segundo, le está encomendado proveer a los ciudadanos de bienes espirituales que les son garantizados por la ley, agilizando el ejercicio del culto que ellos profesan (Duguit, 1907: 16).

No parece claro, por tanto, que la revolución fuese antirreligiosa ni neutral, sino que más bien los aires revolucionarios soplaban reclamando, en primer lugar, la soberanía del pueblo y la legitimidad de la ley. Es decir, la revolución fue más formal, legalista y centrista, y a su vez populistamente instrumentalizadora de la religión a su favor que neutralizadora, irreligiosa o descristianizante ${ }^{13}$. Por ello, sus maniobras se dirigieron de forma directa hacia la recuperación de la soberanía usurpada por la oligarquía eclesiástica, y no contra el dogma de la religión en sí, por lo que primero se interesaba en nacionalizar la Iglesia y someterla al imperio de la ley y la soberanía del Estado.

Cabe destacar una carta del 27 de marzo 1804 remitida por Napoleón Bonaparte a Regnier, su ministro de Justicia, por la que le ordena emitir una circular a los comisarios del Gobierno ante todos los tribunales del orden de lo penal para hacerles saber su intención de no tolerar ninguna rebeldía de la comunión del Estado que lo será igualmente al mismísimo papa, debiendo reprimir toda línea de pensamiento aje-

12. En cursiva en el original (la temporalité).

13. El clero católico insiste en describir los intentos de recuperación de la soberanía y la beligerancia contra su oligarquía como intentos de decristianización, y se felicitan, además, de que hayan sido infructuosos Sevestre (1905: 4). 
na a la autoridad civil; que el Gobierno no reconoce más que la religión católica, apostólica y romana sobre su territorio, así como aquellas religiones reformistas establecidas a lo largo de los siglos. Y que toda aquella religión nueva que pretenda separarse de la comunión de los obispos será considerada como secta y no será tolerada ni reconocida por el Gobierno (Bonaparte, 1861: 307). Es decir, Napoleón asocia el concepto de la comunión eclesiástica al Estado, al haber investido el Estado con la sotana papal asociándolo al oficio eclesiástico.

\section{I La religiosidad y las confesiones entre los tribunales y las tribunas del siglo de la soberanía religiosa}

En sendas ocasiones, los tribunales franceses se enfrentaron a las reclamaciones de las peculiaridades confesionales que demandaban los feligreses en el ejercicio de su derecho, asegurado por el artículo 10 de la declaración de derechos de 1789 .

La primera es la relacionada con el tratamiento del islam y sus peculiaridades procesales, en casación civil (27 de septiembre de 1822) y, unas décadas más tarde, en casación penal, por un caso procedente de Argelia (Cour de Cassation Française, 20 de mayo de 1882, MohamedAmokran-Oukaci). Lejos de adentrarnos en las particularidades de estos casos, lo que nos importa para el presente es que el alto tribunal francés los trataba como sectateur. Es decir, no mencionaba a los musulmanes como creyentes o como devotos de otra fe, sino como miembros de una secta, lo cual puede dar a entender la tolerancia incluso hacia las sectas, o cualquier credo o variante ideológica, por mu- cha reducción categórica que se le diera. Todo ello parecía ser aceptado y debatible en sede del alto tribunal. El derecho a confesar cualquier ideología e imponer libremente su respeto al poder público, tal y como venía propugnando el art. 10 de la declaración de 1789.

Algo similar sucede con el judaísmo y las particularidades de sus ordenanzas, mashfat ivri. La casación civil se enfrentó con el juramento more jodaico en 1846, en la que el alto tribunal transciende la cuestión haciendo declaraciones más utópicas que estrictamente procesales y afirma:

Ya no existe en Francia ninguna desigualdad, ninguna diferencia entre los franceses israelitas y los franceses de otros cultos. Ya no existen para ellos ${ }^{14}$ otras leyes que por nosotros, otro derecho que el nuestro. $Y$ como nosotros, pueden invocar los principios de todas las garantías consagradas y proclamadas por las leyes y la constitución. Hoy, por tanto, los israelitas se encuentran como nosotros, siempre bajo el imperio de este principio general de la presunción de la buena fe. Un suelo y la misma ley protegen su honor y el nuestro ... (Cour de Cassation Française, 8 de marzo de 1846, Cerf c. Gougendheim).

Así fue el escenario decimonónico francés, devoto, sí, pero tolerante, es decir, plural, dejando atrás el monopolio y la exclusividad que venía imponiendo el apostolado católico desde la Edad Media.

La devaluación no venía a ser tanto religiosa ni objetadora de forma directa del dogma católico o cristiano, en general, como de reacción a la oligarquía católica

14. Aun con ello, las referencias al otro que hace el tribunal merecen un análisis metalingüístico ajeno al objetivo del presente trabajo, por lo que quedará pendiente para otro estudio con distinto enfoque. 
y el monopolio ejercido tanto por la Iglesia como por sus tribunales. Era, más bien, un pulso reactivo, anticlerical, político antes que propiamente dogmático o negacionista del catolicismo. Precisamente, la ley de 1802 privaba a la Iglesia de poderes jurisdiccionales, delimitando la soberanía de jurisdicción a los tribunales del Estado. Sin embargo, esta seguía ejerciendo su poder y el monopolio de su dogma ante los tribunales estatales en contra del libre pensamiento y la cultura positivista, tanto contra la difusión de doctrinas que consideraba inmorales como mediante el monopolio educativo escolar.

En 1820, Benjamin Constant aparece entre las voces posrocambolescas y robespierreanas abogando por la libertad de religión, filosofía, literatura, industria y política (Constant, 1872: VI). En la misma década escribe que "la religión debe restablecerse solamente a condición de las necesidades del hombre, y cuando este la requiera ... la naturaleza de la religión es una cosa dentro de la naturaleza, por lo que no permite revestir su cruz con la toga del Estado» (Constant, 1818: 343).

Así, y haciendo suyos los argumentos de Clermont-Tonnerre, los reproduce diciendo:

La religión y el Estado son dos cosas perfectamente separadas cuya unión no puede sostenerse la una en la otra. ... el hombre y sus relaciones con su creador implican poder realizarse mediante uno $u$ otro sistema de ideas que llamamos religión. La religión de cada uno, entonces, es la relación de cada uno con Dios, que puede ser una opinión libre de tomar una religión u otra. ... la religión es de todos los tiempos, de todos los lugares, de todos los gobernantes, su prerrogativa está dentro de la consciencia del hombre, y la consciencia es la única facultad que el hombre no puede sacrificar nunca por una convención social (Constant, 1818: 355-6).
Constant advierte, por tanto, de la posible usurpación de la soberanía del pueblo por la religión, y de que hasta incluso si esa religión se convierte en peligrosa para el Estado, este no debe suscribirla por temor ni complacerla imponiendo sus coacciones al ciudadano por simple previsión de hechos antirreligiosos (Constant, 1818: 353). A la inversa, la liberalización de la conciencia, o su emancipación de la tutela del Estado, se traduce en otro paradigma desarrollado un siglo más tarde en un derecho a desligarse del Estado y de las obligaciones para sostenerlo. Si cada hombre se ha emancipado del Estado, queda libre para hacer todo lo que le convenga cuando no infrinja otro derecho análogo ni exceda de una libertad otorgada a otro conciudadano. Queda perfectamente libre para desligarse del Estado y de sus obligaciones para mantener sus arcas y/o impedir que su parte contributiva se destine al beneficio y/o al servicio de la conciencia del otro (Spencer, 1993: 15).

Todas las perspectivas apuntaban hacia una oposición contra el clero como una legión antagónica con la revolución, la soberanía popular y el culto del Estado supremo postulado por los discursos robespierreanos como único culto que la ley debe ostentar (Mathiez, 1927: 13). Es decir, hasta la mitad del siglo xIx no se puede apreciar tanto la devaluación de los valores religiosos como la hostilidad contra el catolicismo como tales, sino que la oposición se dirige, como ya se ha dicho anteriormente, contra el clero. Tanto la revolución como sus ideólogos se mantenían neutrales con el catolicismo mientras este respetase el deísmo revolucionario como una ideología suprema del Estado ${ }^{15}$. Un

15. En carta del 30 de marzo 1804, Napoleón escribe a Portalis, consejero de Estado, y le refiere su intención de perseguir severamente a los 
Estado de la revolución propuesto a garantizar la libre creencia y que, a su vez, se postula como creyente de una religión más, una religión positiva, la de su propia soberanía y su propio humanismo. No tanto como «una guerra declarada contra el cielo por perder la virtud en la tierra» (Mathiez, 1927: 290).

Auguste Comte lanzará la siguiente definición: "La religión será siempre caracterizada por el estado de armonía plena, propia de la existencia humana, tanto colectiva como individual, cuando todas sus partes son dignamente coordinadas. ... La religión constituye un consenso por el alma comparable con el de la salud del cuerpo» (Comte, 1852: 8).

Es menester subrayar la táctica del tono cordial con la que se alza la ola de irreligiosidad del Estado, más bien dispuesta a investir la religión con todos los valores del alma, como seres devotos, pero emancipados de la tutela del clero y la hegemonía de la Iglesia. Un nihilismo, pero no un ateísmo. Es decir, este paradigma puede ser el principal a la hora de recibir la idea del «laicismo» para evitar ser acosados de blasfemia o idolatría, y escudarse así de la hostilidad directa del clero.

Como tal, la acepción «laico» hasta entonces no aparecía en ningún discurso literario ni en términos de ruptura ni de hostilidad. Comte, en su tratado sobre el sistema político y la institución de la religión humanitaria editado en 1852, no se

enemigos de la religión del Estado invocada por el concordato y la unión papal (Bonaparte,1861: 310-11). Llegó incluso a considerar la rebelión a su nuevo concordato como una rebelión tanto a la religión como a la patria (Bonaparte,1861: 326) y hasta a afirmar al papa, por misiva del 3 de agosto 1804, el compromiso del Estado tanto con la religión como con la autoridad papal (Bonaparte, 1861: 448). refiere de ninguna forma al término «laicismo» ni a la laicidad del sistema político. Toda la construcción teórica hasta el momento giraba entonces en torno a la idea de instaurar un nuevo postulado, una nueva ideología humanista, dotándola de cualquier adjetivo, incluso el de «religioso», pero evitando cualquier forma de choque directo con la Iglesia y ahorrarse así sus hostilidades.

\subsection{Ardores de irreligiosidad y desenlace}

Duguit apunta que la proclamación del dogma de infalibilidad pontifical en 1870 habría sido uno de los detonantes más inmediatos del enfrentamiento entre la Iglesia galicana y la Santa Sede. La galicana, encabezada por el jefe del Estado, se somete a la ley y el Derecho, en oposición a la otra, que se proclama encabezada por un ser infalible. Además, Duguit se refiere a varios incidentes diplomáticos provocados por la proclamación de ese dogma y a un desencuentro entre el presidente y el papa como detonantes del desenlace, ya en los albores del siglo XX (Duguit, 1907: 2) ${ }^{16}$.

No obstante, cabe apuntar a la época de la evolución ${ }^{17}$, iniciada por las elecciones de 1849, y el consecuente plebiscito constitucional de 1851, y a las serias in-

16. Torres Gutiérrez documenta la gestación del texto de la ley de 1905, sus trámites parlamentarios, sus borradores previos y su progreso legislativo (Torres Gutiérrez, 2016).

17. Con la expresión «época de evolución» se hace referencia al periodo de inseminación de las teorías anticlericales iniciada por las elecciones de 1849 y el afloramiento de discursos neutralizadores de la esfera pública de la Iglesia, protagonizados principalmente por Napoleón III, Proudhon, Vacherot, pero no solo por ellos, como se verá enseguida. 
terferencias del clero católico al considerar a Luis Napoleón como un peligro para la Iglesia por la ideología soberanista y positivista que postulaba.

Seguidamente, otro acontecimiento en el ámbito literario puede considerarse el detonante en el mundo intelectual en contra de la hegemonía de la Iglesia. En 1858 son dictadas por los tribunales correccionales dos sentencias de prisión para los autores de los libros La justice... (Proudhon, 1858b, 1858a) y La démocracie (Vacherot, 1858) por atentar contra la moral religiosa (Weill, 1915: 58). Ahí empieza el ardor en las tribunas intelectuales para encauzar la emancipación y la independencia, tanto del Estado respecto de la Iglesia como a la inversa. Es decir, para poner fin a la intertutela que embarga a ambos con esa recíproca servidumbre. Posiblemente podemos apuntar a esa época como el marcador del antes y el después conceptual en la historia etimológica del concepto «laicismo».

\section{Laicismo, un concepto polivalente y con denotación inversa}

La literatura contemporánea sobre el origen del concepto «laicismo» y su uso actual lo remonta literariamente, de forma unánime, a Ferdinand Buisson como promotor de la separación de la fe de los distintos aspectos de la vida pública (Baubérot, 2010, s. f.: 27; Maury, 2012; PeiIlon, 2010). Y es cierto que el referido Buisson, en una carta datada en julio de 1869 y enviada a Victor Hugo, le dice: «El protestantismo no será ni el objetivo ni el medio, yo lo creo como usted, venerado compatriota. La cuestión no está ahí, no es al protestantismo al que le pido que preste atención con toda su fuerza: es a una empresa laica y filosófica por combatir el catolicismo en Francia» (Buisson, 1938: 228) ${ }^{18}$.

Es decir, a Buisson se le define como un propulsor del anticlericalismo y el fin de la oligarquía eclesiástica. Por su parte, Paul Raphael interpreta la idea de Buisson como una lucha para una subversión de la Iglesia, que debería dejar de ser una reunión de fieles compartiendo las mismas convicciones sobre Dios y el mundo para convertirse en un grupo de hombres que pueden diferir en sus opiniones, pero están unidos por un sentimiento de conciencia moral (Buisson, 1938: 230). En definitiva, toda la literatura contemporánea vigente sitúa el laicismo como un término emergente de la Tercera República (1870-1940) y que culmina con la ley de 1905 -denominada hoy ley del laicismo-, que es una aberración literaria, jurídica e histórica, como veremos enseguida.

\section{I Raíces de los misteriosos términos «laico»y «laicismo»}

El primer uso institucional del término «laicismo» lo podemos remontar a 1438 en una carta de Jouvonel des Ursins, ministro de Justicia, a Carlos VII, que le escribe afirmando que: «Usted no es solamente una persona laica, sino también un prelado eclesiástico» (Duguit, 1907: 5-6).

18. Se ha observado una traducción casi literal de este texto para mantener su coherencia con el original, que dice literalmente lo siguiente: «Que le protestantisme ne soit ni le but ni le moyen, je le crois avec vous, vénéré compatriote. La question n'est pas là. Ce n'est pas au protestantism que je vous ai demandé si vous voudriez prêter votre puissant concours: c'est à une entreprise laïque et philosophique pour combattre le catholicisme en France» (Buisson, 1938: 228). 
Seguidamente, en el mismo año, el término aparece en la pragmática de Bourges con la referencia a un título de príncipe laico como jefe de la Iglesia nacional galicana. Incluso refiriéndose al papa León X, Corréard lo describe como un príncipe laico al que le gustaban la caza, la fiesta y la lujuria (Corréard, 1886: 88). O también haciendo referencia a Pío VII como un príncipe laico ordinario (Bignon, 1838a: 124; 1838b: 264). Incluso lo hace Napoleón Bonaparte en una carta del 10 de febrero 1804 dirigida a su ministro de Justicia ordenándole perseguir a todo culpable, sea la que sea su categoría, eclesiástico o laico (Bonaparte, 1861: 240). El uso del término "laico/laicismo» se mantiene en la misma línea, como aquel con el que la Iglesia se refiere a un creyente católico, devoto, pero sin ser ordenado con hábitos eclesiásticos como prelado secular. Así aparece en el Diccionario del derecho canónico de 1888 y reiteradamente en sus sucesivas ediciones como una distinción del pueblo de Dios entre seglares y laicos (Condis y André, 1901: 5-6).

La laicidad, por tanto, no es otra cosa que el sinónimo político de militancia. Devoción es la exteriorización castiza de la fe, y la laicidad es su exteriorización y ejercicio político. Así fue no solamente en el Antiguo Régimen, sino incluso durante el primer siglo y cuarto de la revolución. Latreille, en 1935, en su tesis doctoral documentando las relaciones de Napoleón con la Santa Sede entre 1801 y 1808, en tanto que se refiere a un secular con hábitos y a un civil, lo hace como laico (Latreille, 1935: 65, 83, 147). Es decir, tanto la revolución como su fruto, la República, fueron laicos, sí, pero en el sentido de un laicismo devoto, católico, religioso y cumplidor apostólicamente. El laico, por tanto, no se refería ni al irreligioso ni al negador de la deidad ni al neutro, ni mucho menos al ateo, ni siquiera al nihilista.

\subsection{Laicidad y Dios en la República y sus instituciones}

Como acabamos de demostrar, ni la República ni la Revolución francesa en sus inicios parecen haber sido ni neutros ni mucho menos soberanos, como afirmaban ser en sus discursos primigenios. Napoleón Bonaparte, a bordo de la fragata Oriente durante su navegación hacia Egipto, el 22 de junio de 1798, escribió una orden a sus tropas anunciándoles el cometido de su viaje y dándoles instrucciones sobre cómo actuar, y en ella les dice: «No les contradigáis, tratadles como tratamos a los judíos o a los italianos; respetad a sus muftíes $^{19}$ y a sus imanes tanto como nosotros lo hacemos con los rabinos y los obispos» (Bonaparte, 1860: 256-57). Es decir, por un lado, Napoleón afirma la neutralidad, producto de la existencia de una tolerancia previa, tanto en el vulgo como en las instituciones, y más concretamente entre los militares en Francia. Ello, a pesar del cometido encomendado al jefe del Estado francés desde 1302 de defender a la Madre Iglesia católica y sus prelados, cargo que de pronto es heredado y ejercido por el mismo Napoleón en 1802 -como ya se comentó anteriormente- en su condición de primer cónsul de la República (Duguit, 1907: 5). Es decir, la emergente revolución mantenía el mismo esquema y postulado del concordato de 1516, siendo la católica «Iglesia del Estado y, por consiguiente, hay que defenderla de sus Iglesias riva-

19. Las cursivas son, transliteradas del origen como tal, que se debe a una transliteración del árabe al francés. 
les y contra las pretensiones de la Santa Sede». Todo apunta a que el mantenimiento de la defensa eclesiástica por el Estado se centraba apenas en el sentido de nacionalización. Es decir, contra las pretensiones centralizadoras de la Santa Sede, pero no en contra de las demás Iglesias, credos o confesiones diferentes en términos de tolerancia. Precisamente, el término «laico» es obviado en el lenguaje jurídico y legislativo de las primeras décadas de la revolución, dado que tenía profundas raíces y connotaciones del Antiguo Régimen, quien fue laico a todos los efectos. Es decir, fue laico entendido con visión más conservadora que progresista.

En la carta del 10 de febrero 1804 de Napoleón a su ministro de Justicia, anteriormente citada, el primer cónsul resume la política confesional del Estado y afirma que: «Los principios del Gobierno son reconocer las religiones antiguas establecidas y conforme a este principio no podemos tolerar ni las sectas teofilantrópicas ni a los eclesiásticos que no se reúnan a la comunión de sus arzobispos ni se sometan al concordato» (Bonaparte, 1861: 240).

El paso a la separación emerge entre los discursos de la segunda mitad del siglo XIX, seguidos de los acontecimientos de 1858 antes citados, tras las condenas a Proudhon y Vacherot.

Seguidamente, como ya se comentó, Buisson inicia el uso del término «laicismo» en su campaña para una escuela laica, es decir, rehusando el dominio clerical y luchando por una independencia académica de la oligarquía eclesiástica. Lejos, claramente, de toda acepción antirreligiosa o beligerante con el dogma católico, y así, efectivamente, lo consigue por la promulgación de la Ley Jules Ferry, de 28 de marzo de 1882, que establece, por primera vez, el objetivo de la enseñanza pública como «instrucción moral y cívica» (art. 1), que, además de conocerse como la primera ley de laicidad de la educación, no incluye ninguna alusión al término «laico» ni a «laicismo» más que esa concreción en sus objetivos: instrucción moral y cívica.

Por otro lado, se intensifica la literatura contra la bicefalia del Estado y por la neutralización de la soberanía del dios político. En 1889, Pierre Laffitte escribe en la revista Occidente afirmando que «Dios ahora es una cuestión privada, y no de orden público» (Nicolet, 1982: 234).

\subsection{La ruptura y la emancipación del Estado y de la lglesia}

Como tantos otros conceptos, a la ley de 1905 se la denomina mediáticamente «ley de la laicidad", como referencia a la separación del Estado de las Iglesias. En el artículo primero de la ley se afirma que «la República asegura la libertad de conciencia. Garantiza el libre ejercicio de los cultos bajo las solas restricciones señaladas a continuación dentro del interés y el orden público». Es decir, el Estado deja de postularse públicamente con un credo concreto, como lo hacía en el Antiguo Régimen, y como un asociado clerical al papado y al jefe de la Iglesia nacional. Renuncia, por tanto, al título de encabezar la Iglesia, así como a su carácter nacional y estatal, privatizando la Iglesia del Estado ${ }^{20}$ y, eso sí, re-

20. Es menester reiterar lo que ya se comentó anteriormente, tanto el Antiguo Régimen como la propia revolución se sostenía sobre que «la religión católica es la religión del rey de Francia, la Iglesia católica es una Iglesia nacional y del Gobierno de la que el rey es su jefe y asociado directamente» Duguit (1907: 7). 
nunciando a ser laico. Es decir, en los propios términos y sentidos del concepto de «laico», la ley del 1905 inicia la andadura de neutralidad e irreligiosidad del Estado y pone fin a su laicidad heredada del Antiguo Régimen, desligándose de todo el contenido que alberga el término «laicismo», lastrado desde 1438. Por tanto, la ley de 1905 puede vincularse a cualquier otro término menos al de «laico». Es, de hecho, plenamente antilaica, sin nada que ver con cómo se la reconoce pervertidamente hoy, es decir, como la ley del laicismo o la laicidad.

El Estado no solamente pasa a asegurar la libre creencia y a convertirse en vigilante y espectador de su libre ejercicio, también se declara neutro de conciencia, soberano de sí mismo, sin misticismo ni monopolio de la virtud-espíritu ${ }^{21}$. La declaración también puede entenderse en sentido inverso, como emancipación, dado que en el artículo segundo se niega, además del revestimiento público de toda religión, la subvención y cualquier forma de participación financiera en ninguna actividad religiosa. Es decir, la ley de 1905 es más bien una ley de privatización de la Iglesia del Estado, y supone la emancipación de ambos en todos los sentidos de interdependencia, tanto política como financiera.

La ley de separación de 1905 desarticula globalmente los tres principios -anteriormente comentados- sobre los que se organizaba la Iglesia, al romper la asociación, primero, con la confesión, desnudando así el Estado de investirse una religión concreta, al liberarse de la prerrogativa de su patriarcado y, tercero, al deshacerse de un cometido administrativo,

21. Se conjuga delicadamente «virtud» con «espíritu», dado que desde entonces se concibe la intromisión entre ambos, en usos tanto literarios como conceptuales. como era el servicio público de culto. Sin duda, de ningún modo se relaciona esto con el laicismo, ya que precisamente el laicismo era lo que hacía referencia el Antiguo Régimen, y es lo que venía esa ley a romper. Laico es el devoto civil adscrito al servicio de la Iglesia, como lo era precisamente el rey, un príncipe laico y prelado eclesiástico, que es exactamente lo que viene la ley de separación a negar y a lo que va a poner fin, a la laicidad.

El 13 de marzo de 1907, el decano Duguit interviene en la Escuela de Altos Estudios Sociales de París, a los tres meses de la entrada en vigor de la referida ley de separación de 1905²2, y afirma que «la religión, asunto de conciencia privada, se volvió una cuestión totalmente ajena a la vida política del país, todos los creyentes podrán practicar libremente sus cultos bajo la protección imparcial y neutral del Estado» (Duguit, 1907: 2). Es decir, se pone fin a la laicidad, como violencia material y resto residual del Antiguo Régimen, pasando a neutralizar el Estado tanto la laicidad católica como cualquier otra conciencia religiosa, imponiéndose así con plena soberanía republicana y humanista. La ley de separación, por tanto, marca el antes y el después normativo en cuanto a la amputación de una de las patas del Estado como poder público bicéfalo, al prescindir del servicio de culto como uno de los ejes del bienestar, además de neutralizar la soberanía como un principio normativo más que como un valor utópico.

\subsection{La crítica es inaudible}

Cabe volver a recordar la advertencia de Robespierre, anteriormente referida, en

22. La ley de separación a todos los efectos transitorios entró en vigor el 9 de diciembre 1906. 
su misiva a la Convención Nacional en contra del decreto de reforma financiera. La ruptura se produce nuevamente mediante una ley ordinaria, que transforma el conjunto del sistema, prescinde de una de las patas del servicio público, de una potestad del Estado y de un valor íntimo de los ciudadanos sin contar con el valor constituyente que debería haber tenido. Ni siquiera es elevada a la categoría constitucional junto al resto de las leyes constitutivas de 1875. Un acto que podemos definir como la ruina de principios normativos y como una blasfemia constitucional más que como una idolatría de facto.

Cabe añadir dos críticas más a la ley de 1905. La primera a la que se puede aludir es a la organización territorial que establece el artículo 19 en cuanto a la libertad de circunscripción religiosa. La ley 8 de abril 1802 acordó determinar taxativamente las demarcaciones religiosas del Estado mediante una tabla de equivalencias entre las demarcaciones administrativas y sus correspondientes religiosas, lo que constituía un modo de ejercer la soberanía nacional e imponer la omnipotencia del Estado como único titular tanto de la soberanía como de la organización territorial. Sin embargo, la ley de 1905 liberaliza la organización de las circunscripciones religiosas de forma ajena al Estado. En el artículo 19 aparece la renuncia del Estado a su soberanía y circunscripción única a favor de que las asociaciones religiosas se establezcan geográficamente según consideren ellas mismas necesario para su propia e independiente gestión. Este paradigma puede entenderse como una renuncia a la soberanía, o también a la inversa, una neutralidad por parte del Estado, que se declara así neutral, ajeno, y al margen de toda la gestión religiosa. Como afirmó Duguit, «la religión se ha vuelto una cuestión privada ajena al Estado» (Duguit, 1907: 2). Por tanto, el Estado se abstiene hasta de organizar las circunscripciones religiosas, dejándolas al libre albedrío de las asociaciones religiosas, que se establecerían como independientes a todos los efectos.

El otro aspecto de la crítica se refiere a la contradicción constitucional directa entre la ley de 1905 y el inciso final del artículo primero de la ley constitucional del 16 de julio de 1875, que establecía que «al domingo siguiente de concluirse el periodo de sesiones, una oración pública será rendida a Dios en las iglesias y los templos en acción de gracias por su ayuda a los trabajos de las asambleas» ${ }^{23}$. Es decir, lo que una ley con rango constitucional establecía, otra ley de carácter ordinario venía a desmantelarlo y dejarlo sin efecto: el vínculo afectivo entre el Estado y la tarea eclesiástica. Fuera de esta mención, ninguna de las leyes constitucionales formantes de la Constitución de la Tercera República se refiere a la organización eclesiástica ni a su conjugación con los poderes públicos. Aunque es manifiesta la contradicción entre este precepto de acción de gracias y la ley de separación, sin embargo, ambos siguieron vigentes y convivientes durante más de medio siglo, prácticamente hasta 1940, cuando se derogan las leyes constitucionales de 1875.

\section{Epílogo}

Al referirse al laicismo sobreviven hoy versiones antagónicas, ambiguas, pero viralmente populistas. Como ya hemos visto en el curso histórico, el término «lai-

23. En el texto original: «Le dimanche qui suivra la rentrée, des prières publiques seront adressées à Dieu dans les églises et dans les temples pour appeler son secours sur les travaux des assemblées». 
co», hasta el 9 de diciembre 1905, día de la promulgación de la ley de emancipación, se refería a un principio constitucional del Estado, como devoción católico-apostólica, que desde entonces es expulsado del ordenamiento jurídico, quedando como un término teocrático ajeno a la normatividad. Sin embargo, lingüísticamente sobreviven versiones contradictorias de su definición. Hoy, el Diccionario Larousse lo define como «concepción y organización de la sociedad fundada sobre la separación de la lglesia del Estado y que excluye las Iglesias del ejercicio de todo poder político o administrativo, y en particular el de la organización de la enseñanza». Es decir, en línea con los preceptos asentados por la ley de 1905, y muy ajeno al uso histórico del término, tanto bajo el Antiguo Régimen como durante todo el siglo xIx. El Oxford English Dictionary, por su parte, traduce laicismo como secularismo y lo define como secularidad moderna, hostilidad hacia el cristianismo, resultante de no creer en nada, pero creer en todo: «Modern secularity's hostility to Christianity results, not in belief in nothing, but in belief in anything». Por lo que respecta al Diccionario de la lengua española que publica la $R A E$, es definido como «principio que establece la separación entre la sociedad civil y la sociedad religiosa». Es decir, estamos ante un entramado de contradicciones que no coinciden con nada. Y, sin embargo, por laicismo se entiende la ley del 1905, y laicismo se traduce como secularismo en inglés, sin que de ninguna forma signifique lo mismo. Sumado a ello, la propia Iglesia católica, en el decreto Apostolicam Actuositatem de 1965 sobre el apostolado de los laicos (Pablo II, 1965), define nuevamente a los laicos como aquellos devotos feligreses de la Iglesia sin voto secular. Es decir, con el mismo uso histórico que siempre se le daba bajo el Antiguo Régimen y durante el siglo xIX.

\section{Conclusiones}

Laico es el perseverante devoto católico. La ley del 1905 es la ley de ruptura con el laicismo, con la religiosidad y con todas las oligarquías teocráticas. Una ley de emancipación y neutralización del Estado, su soberanía, y de la tutela y la servidumbre impuesta por la oligarquía religiosa y, a su vez, de la liberalización de las oligarquías de la tutela pública. No es, por tanto, ley de descristianización ni mucho menos de laicismo, sino todo lo contrario, es la ley de ruptura con el laicismo del Antiguo Régimen y sus residuos lastrados durante el primer siglo de la revolución. Otra cosa es su contradicción frontal con las leyes constitucionales de 1875 y las irregularidades de cohesión normativa que pudo haber causado o puesto en evidencia desde el esquema de idolatría dentro del conjunto normativo ${ }^{24}$.

En cambio, el laicismo de la Quinta República emerge como una deconstrucción, agencia del Antiguo Régimen, lejos de ser una negación frontal de la neutralidad o la irreligiosidad concebida y asentada por la ley de 1905. Una interpretación, a cobro revertido, de la laicidad clásica que se introduce en el artículo primero de la Constitución de 1958 retorciendo la normatividad tendencial del mismo artículo primero con el resto del cuerpo constitucional, como el conjunto del sistema normativo. Parece ser más bien una rectificación de la contradicción acontecida por la ley de 1905 y una reconstrucción del artículo primero de la ley constitucional de 1875, un Estado laico como siempre lo fue en el Antiguo Régimen. Una forma

24. Se refiere a conjunto normativo, evitando el calificativo sistema, al cuestionarse la didáctica normativa entre la referida ley de 1905 y el ordenamiento constitucional de 1875. 
de idolatría de la constitución dentro del mismo cuerpo constitucional, un ejemplo más que contribuye a la teoría de la idolatría constitucional (Jones, 2020).

La constitución es una tumba vacía, una imagen poderosa creada por el constituyente y expuesta a la potencia de la interpretación que le da el espectador desde su sensación cambiante: sus emociones subjetivas y sus constructos cognitivos. Toda norma, toda ley es carente de violencia propia, de imperativo, más bien está cargada de súplica para ser mantenida y comprendida como tal, una constitución, una imagen latente, plagada de ambigüedad y expuesta a la adoración y el esplendor, sin que suponga, en ningún caso, un esquema de nihilismo. El paradigma de fe en la constitución (Levinson, 2011) es ajeno al paradigma tradicional de fe basado en la incertidumbre. La fe en la constitución se basa en la tactilidad, a pesar de la invisibilidad-intangibilidad del Estado (Burdeau, 1970), la constitución, siendo tangible, no consiste en una escritura sagrada scriptor no susceptible de interpretación (Grey, 1984; Ravitch, 2009), sino que está supeditada a la ductilidad de la interpretación (Zagrebelsky, 1995) mediante la fe. Una fe dialéctica automatizada con el resto de los componentes del sistema normativo, sin dar lugar ni a contradicción ni a idolatría.

No hay idolatría sin que haya un vaciamiento previo de la existencia en forma de sublevación parasitaria. No consiste en parábola de existencia ni en deconstrucción del ser previo. El idólatra emerge del concepto preexistente y a su propia costa, y no surge de sí mismo como un ser ex post facto. Consiste en un mecanismo dinámico desde un paradigma de actuarvencer cediendo del ser a su antagónico idolatrado. No se asemeja al modelo ateís- ta asesino del ser supremo -Dios en la teología, o la constitución en el derecho- para su sustitución, sino que impera como coexistencia, convivencia con el ser primario. Idolatrar un valor constitucional no supone derogar su antagónico, sino sublevarse a su contenido, deslumbrando el resto de los valores constitucionales mediante un esquema de autodestrucción: de la propia constitución, pero también, y peligrosamente, del conjunto de la tendencia automatizada del sistema normativo, como lo hizo la ley de 1905. Una forma de centrifugación consistente en aprovechar la propia dinámica de la normatividad constitucional para expulsar el resto de los valores antagónicos. Por tanto, la idolatría constitucional derivada del laicismo es nihilismo, como se asentó la idea de este (Nancy, 2003: 116), y nada tiene que ver con el ateísmo renegador ni con otras perspectivas de dualidad teológica.

En el presente caso, se ha demostrado cómo un concepto dotado de unas dimensiones y significados históricos del Antiguo Régimen y el primer siglo de la revolución, y después de haber sido excluido del ámbito jurídico por la ley de 1905, se resucitó para retornar a la Constitución de 1958. Emergió, además, con distinta dotación de significado antagónico para ser hoy el postulado más rentable políticamente. Este esquema respondería más al paradigma de blasfemia constitucional que al de la mera idolatría. Queda pendiente de ulteriores trabajos el análisis del subsiguiente periodo -el del nihilismo, entre 1905-1958-, un periodo que podemos dominar de neologismo conceptual por el que el laicismo resucita con nueva dotación, y se resalta al artículo primero de la Constitución de 1958 con dimensiones totalmente contradictorias con su bagaje etimológico, los de la estructura constitucional y la del propio artículo primero. 


\section{Bibliografía}

Alnasir, S. (2019). Concepto jurídico, Religión y Secularidad: Los casos de Israel, Egipto e Iraq. Madrid, Universidad Carlos III de Madrid.

Alnasir, S. (2021a). "Calamidades del Derecho (post)Colonial y su Orientalismo: Religión, Identidad y libertad individual en Egipto, Iraq y Túnez", Boletín Mexicano de Derecho Comparado, 158, 485-519. Disponible (05/06/2021) en: https://doi.org/10.22201/ iij.24484873e.2020.158.15627.

Alnasir, S. (2021b). "Introspección antropológica en las prácticas y usos sociales, religiosos, identitarios y de colonialidad entre Egipto, Iraq y $\mathrm{Si}$ ria", Anales de Antropología, 55(2), 195-209. https://doi.org/10.22201/ iia.24486221e.2021.78433.

Baubérot, J. (s. f.). La laicité en France, Histoire et défis actuels (pp. 27-48). Disponible en: https://utcp.c.u-tokyo.ac.jp/publications/pdf/UTCPBooklet7_027-048_.pdf

Baubérot, J. (2010). Histoire de la laïcité en France. Presses Universitaires de France. Disponible (05/06/2021) en: https:// www.cairn.info/histoire-de-la-laicite-enfrance--9782130581253.htm

Bignon, L.-P.-É. (1838a). Histoire de France sous Napoléon: Deuxième époque, depuis la paix de Tilsitt, en 1807, jusqu'en 1812 (Vol. 7), Paris, Firmin Didot.

Bignon, L.-P.-É. (1838b). Histoire de France sous Napoléon: Deuxième époque, depuis la paix de Tilsitt, en 1807, jusqu'en 1812 (Vol. 9), Paris, Firmin Didot.

Bonaparte, N. (1858). Correspondance de Napoléon ler: Vol. I, Paris, Plon. Disponible (05/06/2021) en: https://gallica.bnf.fr/ ark:/12148/bpt6k6296221w
Bonaparte, N. (1859). Correspondance de Napoléon ler.: Vol. III, Paris, Plon. Disponible (05/06/2021) en: https://gallica. bnf.fr/ark:/12148/bpt6k6295853m

Bonaparte, N. (1860). Correspondance de Napoléon ler: Vol. IV. Imprimerie Impérial. Disponible (05/06/2021) en: https://gallica.bnf.fr/ark:/12148/bpt6k9636650x.

Bonaparte, N. (1861). Correspondance de Napoléon ler.: Vol. IX, Paris, Plon. Disponible (05/06/2021) en: https://gallica. bnf.fr/ark:/12148/bpt6k6294056s

Buchez, P.-J.-B. (1835). Histoire parlementaire de la révolution française, ou, Journal des Assemblées nationales depuis 1789 jusqu'en 1815, la narration des événemens. Paulin.

Buisson, F. (1938). Une lettre de Ferdinand Buisson à Hugo sur la laïcité, 1869. En La Révolution de 1848 et les révolutions du XIXe siècle (Vol. 35, pp. 228-231). Persée - Portail des revues scientifiques en SHS. Disponible (05/06/2021) en: https://www. persee.fr/doc/r1848_1155-8806_1938_ num_35_167_1328_t1_0228_0000_1

Burdeau, G. (1970). L'État, Paris, Le Seuil.

CCF Cerf c. Gougendheim, (Cour de Cassation Française 8 de marzo de 1846).

CCF Mohamed-Amokran-Oukaci, (Cour de Cassation Française 20 de mayo de 1882).

Commaille, J. (1991). Normes Juridique et Régulation sociale retour à la sociologie générale. En F. Chazel \& J. Commaille (Eds.), Normes juridiques et régulation sociale ( $\mathrm{p}$. 13), Paris, L.G.D.J.

Comte, A. (1852). Système de politique positive ou Traité de sociologie, instituant la religion de l'humanité: Vol. II, Paris, CarriIlan. Disponible (05/06/2021) en: https:// gallica.bnf.fr/ark:/12148/bpt6k61194887 
Conde, F. J. (1935). El pensamiento político de Bodino. Anuario de historia del derecho español, 12, 5-96. Disponible (05/06/2021) en: https://dialnet.unirioja. es/servlet/articulo?codigo=2057266

Condis, P., \& André, M. (1901). Dictionnaire de droit canonique et des sciences en connexion avec le droit canon: Vol. II (III), Paris, Hippolyte Walzer.

Constant, B. (1818). Collection complète des ouvrages, publiés sur le gouvernement représentatif et la constitution actuelle de la France: Formant une espèce de cours de politique constitutionnelle: Vol. I, Paris, Plancher.

Constant, B. (1872). Collection des ouvrages publiés sur le gouvernement représentatif: Vol. I (É. Laboulaye, Ed.; II), Paris, Plancher.

Corréard, F. (1886). Histoire nationale et notions sommaires d'histoire générale, depuis le milieu du XVe siècle jusqu'à la mort de Louis XIV, Paris, Masson. Disponible (05/06/2021) en: https://gallica.bnf. fr/ark:/12148/bpt6k98178941/f8.item

Duguit, L. (1907). Le régime du culte catholique antérieur à la loi de séparation et les causes juridiques de la séparation. Conférence fait à l'École des Hautes-Etudes sociales, le 13 mars 1907, Paris, Librairie de la Société du Receil Sirey et du Journal du Palais.

Duguit, L. (1918). Manuel de droit constitutionnel (III), Paris, Ancienne Libraire Fontemoing.

Duguit, L. (1928). Traité de Droit Constitutionnel: Vol. I/ (III), Paris, Ancienne Libraire Fontemoing.

Engisch, K. (1960). El ámbito de lo no jurídico (E. Garzón Valdés, Trad.), Córdoba, Universidad Nacional de Córdoba.
Grey, T. C. (1984). "The Constitution as Scripture", Stanford Law Review, 37(1), 1-25. Disponible (05/06/2021) en: https:// doi.org/10.2307/1228651

Hobbes, T. (1999) [1660]. Tratado sobre el ciudadano (J. Rodríguez Feo, Trad.), Madrid, Trotta.

Jones, B. C. (2020). Constitutional Idolatry and Democracy: Challenging the Infatuation with Writtenness, Massachusetts, Edward Elgar Publishing.

Juri, Y. (2020). "La soberanía como fundamento de la república en Jean Bodin: Una perspectiva jurídica", Scripta Mediaevalia - Revista de Pensamiento Medieval, 13(1). Disponible (05/06/2021) en: http://revistas.uncu.edu.ar/ojs/index. php/scripta/article/view/3594/2890

Kelsen, H. (2000) [1934]. Teoría Pura del Derecho (M. Nilve, Trad.), Buenos Aires, Eudeba.

Latreille, A. (1935). Napoléon et le SaintSiège, 1801-1808: L'ambassade du Cardinal Fesch à Rome, Paris, Félix Alcan. Disponible (05/06/2021) en: https://gallica.bnf.fr/ark:/12148/bpt6k3384102x

Levinson, S. (2011). Constitutional Faith, Princeton, Princeton University Press.

Malberg, C. (1962). Contribution à la théorie Générale de l'État, Paris, CNRS.

Mathiez, A. (1927). La corruption parlementaire sous la terreur (II), Paris, Armand Colin.

Maury, L. (2012). Ferdinand Buisson et La Foi laïque. Bibnum. Textes fondateurs de la science. Disponible (05/06/2021) en http:// journals.openedition.org/bibnum/800

Müller, J.-W. (2012). Militant Democracy. En M. Rosenfeld \& A. Sajó (Eds.), The Oxford Handbook of Comparative Constitutional 
Law. Oxford University Press. Disponible (05/06/2021) en: https://doi.org/10.1093/ oxfordhb/9780199578610.013.0062

Müller, J.-W. (2016). "Protecting Popular Self-Government from the People? New Normative Perspectives on Militant Democracy", Annual Review of Political Science, 19(1), 249-265. Disponible (05/06/2021) en: https://doi.org/10.1146/ annurev-polisci-043014-124054

Nancy, J.-L. (2003). Au fond des images, Paris, Galilée.

Nicolet, C. (1982). L'idée républicaine en France, 1789-1924: Essai d'histoire critique, Paris, Gallimard.

Pablo II. (1965). Decreto Apostolicam Actuositatem sobre el Apostolado de los Laicos. Vaticano. Disponible (05/06/2021) en: http://www.vatican.va/archive/hist councils/ii_vatican_council/documents/ vat-ii_decree_19651118_apostolicamactuositatem_sp.html

Peillon, V. (2010). Une religion pour la République: La foi laïque de Ferdinand Buisson, Paris, Seuil.

Pendás, B. (2020). "Soberanía: El eterno retorno de Juan Bodino", Revista de las Cortes Generales, 105-124. Disponible (05/06/2021) en: https://doi. org/10.33426/rcg/2020/109/1527

Proudhon, P.-J. (1858a). De la justice dans la Révolution et dans l'Église, BruxeIles, Libraire de l'Office de Publicité.

Proudhon, P.-J. (1858b). La justice poursuivie par l'Église: Appel du jugement rendu par le tribunal de police correctionnelle de la Seine, le 2 juin 1858, contre P.-J. Proudhon, Bruxelles, Libraire de I'Office de Publicité.
Robespierre, M. (1840). Oeuvres de Maximilien Robespierre: Vol. I (A. Laponneraye, Ed.), Paris, Fauboug Saint-Denis. Disponible (05/06/2021) en: https://gallica.bnf.fr/ark:/12148/bpt6k1411602m

Sevestre, É. (1905). L'histoire, le texte et la destinée du Concordat de 1801, Paris, Lethieleux ed.

Spencer, H. (1993). Le droit d'ignorer l'état, Paris, Les Belles Lettres.

Torres Gutiérrez, A. (2016). "La Ley de Separación de 1905: Luces y sombras en la génesis de la idea de laicidad en Francia", Anuario de historia de la Iglesia, 25, 165-192.

Troper, M. (1994). Pour une Théorie Juridique de l'État, Paris, Presses Universitaires de France.

Troper, M. (2001). La théorie du Droit, Paris, Presses Universitaires de France.

Vacherot, É. (1858). La démocratie, Paris, Chamerot.

Viehweg, T. (1964). Tópica y Jurisprudencia (L. Diez-Picazo Ponce de Leon, Trad.), Madrid, Taurus.

Weber, M. (2014). Economía y sociedad (J. M. Echavarría, J. R. Farella, E. Ímaz, E. G. Máynez, \& J. F. Mora, Trads.), Mexico, Fondo de Cultura Económica.

Weill, G. (1915). "L'anticléricalisme sous le socond Empire", Revue des études napoléoniennes, VIII(2), 56-84. Disponible (05/06/2021) en: https://gallica.bnf.fr/ ark:/12148/bpt6k15484b

Zagrebelsky, G. (1995). El derecho dúctil: Ley, derechos, justicia (M. Gascón, Trad.), Madrid, Trotta. 
